\title{
Article
}

\section{The Glutamate Receptor Plays a Role in Defense against Botrytis cinerea through Electrical Signaling in Tomato}

\author{
Shuxian Feng ${ }^{\dagger}$, Caizhe Pan ${ }^{\dagger}$, Shuting Ding, Qiaomei Ma, Chaoyi Hu, Ping Wang and Kai Shi * \\ The Department of Horticulture, Zhejiang University, Hangzhou 310058, China; 21916054@zju.edu.cn (S.F.);

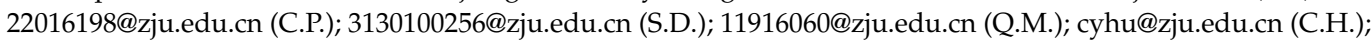 \\ 11916061@zju.edu.cn (P.W.) \\ * Correspondence: kaishi@zju.edu.cn; Tel.: +86-0571-88982383 \\ + These authors have contributed equally to this work.
}

Citation: Feng, S.; Pan, C.; Ding, S.; $\mathrm{Ma}$, Q.; Hu, C.; Wang, P.; Shi, K. The Glutamate Receptor Plays a Role in Defense against Botrytis cinerea through Electrical Signaling in Tomato. Appl. Sci. 2021, 11, 11217 https://doi.org/10.3390/ app112311217

Academic Editor: Huasen Wang

Received: 8 November 2021

Accepted: 24 November 2021

Published: 25 November 2021

Publisher's Note: MDPI stays neutral with regard to jurisdictional claims in published maps and institutional affiliations.

Copyright: (c) 2021 by the authors. Licensee MDPI, Basel, Switzerland. This article is an open access article distributed under the terms and conditions of the Creative Commons Attribution (CC BY) license (https:// creativecommons.org/licenses/by/ $4.0 /)$.

\begin{abstract}
Plant glutamate-like receptor genes (GLRs) are homologous to mammalian ionotropic glutamate receptors genes $(i G l u R s)$. Although GLRs have been implicated in plant defenses to biotic stress, the relationship between GLR-mediated plant immunity against fungal pathogens and electrical signals remains poorly understood. Here, we found that pretreatment with a GLR inhibitor, 6,7-dinitriquinoxaline-2,3-dione (DNQX), increased the susceptibility of tomato plants to the necrotrophic fungal pathogen Botrytis cinerea. Assessment of the glr3.3, glr3.5 and glr3.3/glr3.5 double-mutants upon B. cinerea infection showed that tomato GLR3.3 and GLR3.5 are essential for plant immunity against B. cinerea, wherein GLR3.3 plays the main role. Analysis of the membrane potential changes induced by glutamate (Glu) or glycine (Gly) revealed that amplitude was significantly reduced by knocking out GLR3.3 in tomato. While treatment with Glu or Gly significantly increased immunity against $B$. cinerea in wild-type plants, this effect was significantly attenuated in glr3.3 mutants. Thus, our data demonstrate that GLR3.3- and GLR3.5-mediated plant immunity against $B$. cinerea is associated with electrical signals in tomato plants.
\end{abstract}

Keywords: glutamate receptor-like; necrotrophic pathogens; electrical signal; Botrytis cinerea; Solanum lycopersicum

\section{Introduction}

Plants that grow in a natural environment are continuously threatened by a wide variety of pathogens. These biotic stressors affect crop production and often cause economic losses. As plants lack mobility, they have acquired a range of signal-transduction systems during evolution to effectively mitigate the adverse effects of environmental changes. The faster these signals maneuver, the more likely it is that plants will adapt and resist the incoming stress. The signals reported so far include calcium flow, ROS (reactive oxygen species), electrical signals, etc. [1-5], which react within seconds or minutes.

Plant glutamate-like receptor genes (GLRs) are homologous to mammalian ionotropic glutamate receptors genes $(i G l u R s)$, which trigger electrical and $\mathrm{Ca}^{2+}$ signal cascades $[3,6]$. Plant GLRs are hypothesized to have ligand-binding as well as ion channel activity. GLRs have 20 family members in Arabidopsis [7] and 13 members in rice [8]. There are 13 full-length GLR genes in tomato plants [9].

Importantly, GLRs are involved in the response of plants to biotic stress. For instance, AtGLR3.3 is a vital module of plant immunity against the bacterial pathogen $P$. syringae pv. tomato DC3000 (Pst DC3000), the Oomycete Hyaloperonospora arabidopsidis, and the insect Spodoptera littoralis [10-12]. In addition, Wang et al. (2019) reported that GLR3.5 functions in tomato defense against the root-knot nematode (RKN) Meloidogyne incognita [13]. Overexpression of radish GluR-complementary DNA in Arabidopsis plants enhances resistance to a necrotic fungal pathogen, B. cinerea. However, Arabidopsis glr3.3 mutants do not 
demonstrate increased vulnerability to the fungal pathogen in comparison with Col-0. Thus, the role of GLRs in plant immunity against fungal pathogens remains controversial.

Plant GLRs are involved in the generation and transmission of electrical signals. The existence of electrical signals in plants was discovered by Burden-Sanderson and Charles Darwin $[14,15]$. They are a rapid-response signals generated by the instantaneous change in the electric potential gradient on the plasma membrane or alveolar leaf membrane [16]. All plants can produce long-distance electrical signals, which play a role in the communication of diverse tissues and organs, leading to the integration of environmental responses $[17,18]$. In recent years, the function of electrical signals in GLR-mediated plant resistance to biotic stress has attracted much attention [19]. In Arabidopsis, insects feeding on leaves can cause changes in the surface potential, which lead to the expression of several key jasmonate (JA)inducible regulatory genes in the adult phase of plants [3]. Root-knot nematode attack on tomato roots causes the transfer of electrical and ROS signals from roots to leaves, resulting in an accumulation of JAs in leaves [13]. Farmer et al. (2014) proposed a hypothesis that distal JA synthesis in plants upon wounding was dependent on clade 3 GLR-mediated electrical signals [20]. However, the relationship between electrical signals and GLRinduced plant immunity against fungal pathogens has not been fully substantiated.

The tomato (Solanum lycopersicum L.) ranks as one of the world's most significant cultivated crops in terms of economic importance [21]. Nonetheless, fungal diseases have a negative impact on tomato production, resulting in substantial economic losses [22]. In particular, Botrytis cinerea, a typical necrotrophic fungus, has been considered to be in second place in the top 10 fungal pathogens in molecular plant pathology [23]. It has a wide host range and can infect over 200 plant species, including a variety of cash crops [24]. $B$. cinerea can cause a significant decline in tomato yield and post-harvest fruit quality [25]. However, a tomato variety with broad resistance to $B$. cinerea has not been developed yet. Thus, understanding the molecular mechanisms of tomato resistance to $B$. cinerea is particularly important.

There are 13 full-length GLR genes in tomato plants. In this study, GLR3.3 and GLR3.5, which play positive roles in cold tolerance [26] and defense against RKNs [13], were functionally characterized in regard to tomato plant immunity against $B$. cinerea. We found that GLR3.3 and GLR3.5 are important players in plant immunity against B. cinerea in tomato, possibly through binding to ligand glutamate (Glu) or glycine (Gly), thereby triggering electrical signals. This finding has intrinsic scientific value, with potential for developing new strategies for increasing crop resistance to B. cinerea.

\section{Materials and Methods}

\subsection{Plant Materials, Growth Conditions, and Chemical Treatments}

The tomato lines (CRISPR-Csa9-edited lines of $g l r 3.3, g l r 3.5$, and $g l r 3.3 / 3.5)$ used in this study were in the cv Ailsa Craig (AC) wild-type (WT) background, as reported previously [27]. In the case of soil-less substrate culture, tomato plants were cultivated in pots that contained a mixed substrate (vermiculite: peat, 1:3, $v / v$ ) and fertilized with Hoagland's nutrient solution. In the case of hydroponic culture, tomato seeds were initially germinated in trays filled with a mixed substrate (vermiculite: perlite, 1: 1, v/v) and, after emergence, seedlings were transferred to plastic containers having $1.5 \mathrm{~L}$ capacity (four seedlings per container). The containers were filled with half-strength Enshi nutrient solution, which was continuously ventilated by aerating the air from an air pump [21]. The following were the growing conditions: $14 \mathrm{~h}$ light $/ 8 \mathrm{~h}$ dark photoperiod; $24^{\circ} \mathrm{C} / 20^{\circ} \mathrm{C}$ day/night temperature; and $400 \mu \mathrm{mol} \mathrm{m}^{-2} \mathrm{~s}^{-1}$ PPFD (photosynthetic photon flux density). Four-week-old tomato plants were subjected to treatments.

For DNQX (6,7-dinitriquinoxaline-2,3-dione, GLRs inhibitor) pretreatment assay, the WT plants were treated by foliar spray with $1 \mathrm{mM}$ DNQX or $\mathrm{H}_{2} \mathrm{O}$ as control, $12 \mathrm{~h}$ prior to $B$. cinerea inoculation. Glu and Gly pretreatment assays were performed as the glr3.3 mutants and WT plants were treated with $20 \mathrm{mM} \mathrm{Glu}, 20 \mathrm{mM} \mathrm{Gly}$, or $\mathrm{H}_{2} \mathrm{O}$ as control once per 
day on both the abaxial and adaxial surfaces of leaves. Two days after pharmacological treatment, the plants were subjected to pathogen inoculation.

\subsection{Pathogen Inoculation and Disease Symptom Assays}

The B. cinerea strain BO5-10 was used in this study. The inoculation was performed using a suspension of $B$. cinerea at a density of $2 \times 10^{5}$ spores $\mathrm{mL}^{-1}$ [28]. The whole-leaf portion of tomato plants was sprayed with the suspension. The inoculated plants were placed in a sealed box to maintain humidity of about $90 \%$. The temperature and light were the same as in normal culture conditions.

After pathogen inoculation, B. cinerea actin mRNA accumulation was quantified at 1 day post-inoculation (dpi) [29]. Chlorophyll fluorescence was measured with a chlorophyll fluorometer (IMAG-MAXI; Heinz Walz) at 3 dpi. The photochemical quantum efficiency of PSII (ФPSII) was analyzed as Fm'-F/Fm' [30].

\subsection{Subcellular Localization}

GLR3.3 and GLR3.5 gene fragments were amplified using the primers listed in Supplemental Table S1 and cloned into a pAC402 vector with a green fluorescent protein (GFP) tag [31]. Agrobacterium strain GV3101, carrying plasmids, and Agrobacterium, carrying FLS2-mCherry as a plasma membrane localization marker, were transiently co-expressed in the transgenic Nicotiana benthamiana (expressed with histone 2B-mCherry for marking the nucleus localization), as previously described [32]. At 2 days after infiltration, the fluorescent signals of GFP- or mCherry-tagged proteins were assessed in leaves, using a Zeiss LSM 780 confocal microscope at previously described excitation/emission wavelengths [28].

\subsection{RNA Isolation, Transcription, and qRT-PCR}

Total RNA was isolated from tomato leaves using the RNAsimple Total RNA Kit (Tiangen, China) and reverse-transcribed using the ReverTra Ace qPCR RT Master Mix (Toyobo, Japan). The qRT-PCR process was carried out using the LightCycler 480 Real-Time PCR System (Roche, Switzerland). The reaction system was performed as described in the previous experiment [28]. The specific primers for the B. cinerea actin gene and the internal control tomato actin gene are listed in Supplemental Table S1.

\subsection{Electric Potential Recording}

Hydroponic tomato plants at the four-leaf stage were used for electrical potential recording. Borosilicate glass capillaries with an outside diameter of $1.5 \mathrm{~mm}$ and an inner diameter of $0.86 \mathrm{~mm}$ (Sutter Instrument Company, America) were fashioned into glass microelectrodes with a tip diameter of around $0.5 \mathrm{~mm}$ for intracellular cytoplasmic potential measurements. An APE-2 vertical micropipette puller (Narishige, Tokyo, Japan) was used to pull capillaries after heating. Microelectrodes were filled with $1 \mathrm{M} \mathrm{KCl}$ and inserted into the mesophyll cells of a leaf. The leaf was submerged with the basic solution (composed of $5 \mathrm{mM}$ MES, $0.5 \mathrm{mM} \mathrm{CaSO}_{4}, 0.05 \mathrm{mM} \mathrm{KCl}$, and $\mathrm{pH}$ 6.0) [13], which was performed as shown in Supplement Figure S1. Each electrode was connected to a differential amplifier. Two dual-channel amplifiers (FD223 and Duo773, World Precision Instruments) were used to detect the signals. The hydroponic solution was replaced by the same solution added $2 \mathrm{mM}$ Glu or $2 \mathrm{mM}$ Gly, using the infusion tube, when the value of measured membrane potential was stable. Amplitudes are potential differences relative to the baseline before the changes.

\subsection{Statistical Analysis}

The experiments were conducted via a completely randomized design, and a minimum of three replicates was used in each experiment. Unless otherwise stated, for every biological replication, two leaves from each of two plants were combined and used as an independent sample. Three separate experiments were carried out independently. We ran 
an analysis of variance on the data using SAS software version 8 (SAS Institute), and then used Tukey's test to determine significance at the $5 \%$ level.

\section{Results}

\subsection{Pretreatment with a GLR Inhibitor Increases the Susceptibility of Tomato to B. cinerea}

To explore the role of GLRs in plant defense against $B$. cinerea, the tomato plants were sprayed with DNQX or $\mathrm{H}_{2} \mathrm{O}$ (control), $12 \mathrm{~h}$ prior to inoculation with $B$. cinerea. At $3 \mathrm{~d}$ i with $B$. cinerea, the inoculated leaves exhibited visible disease lesions. The $B$. cinerea infection-induced damage to leaves was assessed using chlorophyll $a$ fluorescence imaging to determine the deviations in the quantum yield of photosystem II (ФPSII) (Figure 1a,b). After inoculation with B. cinerea, the $\Phi P S I I$ significantly decreased. Notably, the value of ФPSII in the DNQX-treated plants was lower than that in the control. DNQX treatment also increased the abundance of $B$. cinerea actin $\mathrm{mRNA}$ in leaves (Figure 1c). These findings indicate that GLRs positively regulate plant immunity against $B$. cinerea in tomato plants.

(a)

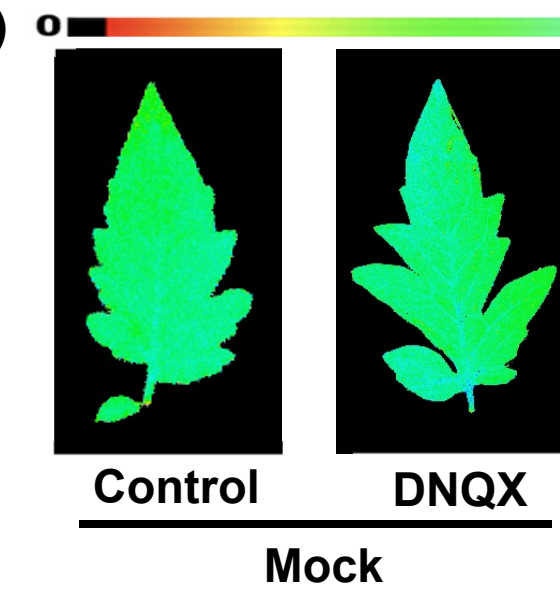

(b)

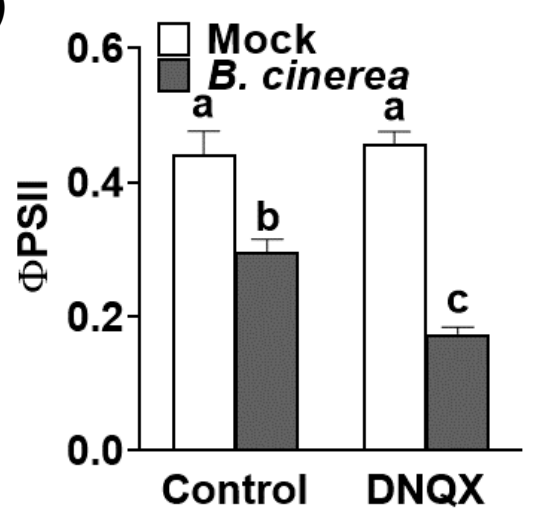

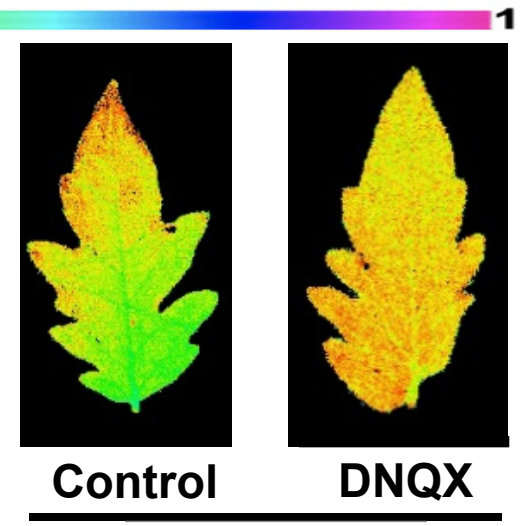

B. cinerea

(c)

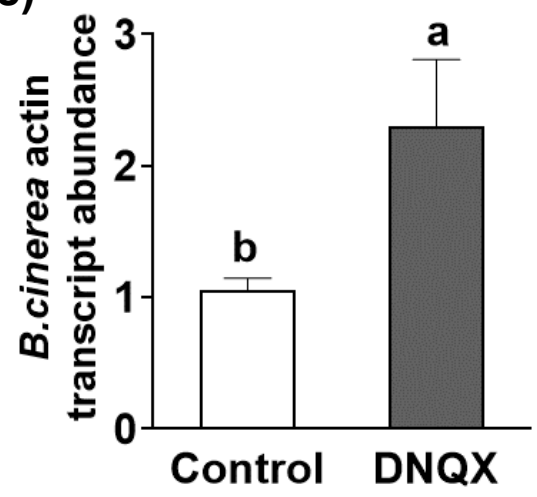

Figure 1. DNQX treatment increases the susceptibility of tomato to B. cinerea. Four-week-old tomato plants were treated with $1 \mathrm{mM}$ DNQX or $\mathrm{H}_{2} \mathrm{O}, 12 \mathrm{~h}$ prior to inoculation with $B$. cinerea: (a) pseudocolor images of tomato leaves showing $\Phi$ PSII at $3 \mathrm{dpi}$; (b) quantitative values of $\Phi$ PSII at $3 \mathrm{dpi}$; (c) transcript abundance of B. cinerea actin in tomato leaves inoculated with $B$. cinerea at $1 \mathrm{dpi}$. The results in panels $(\mathbf{b}, \mathbf{c})$ are presented as mean values $\pm \mathrm{SD} ; n=4$. Statistically significant differences between treatments ( $p<0.05$, Tukey's test) are shown by different letters. The experiments described above were carried out three times, with the same findings each time.

\subsection{Subcellular Localization of GLR3.3 and GLR3.5}

Tomato GLR3.3 and GLR3.5 are homologous to Arabidopsis GLR3.3 and GLR3.6, respectively [9], which have been reported to participate in response to nematode attack and cold tolerance in tomato. To determine the subcellular localization of tomato GLR3.3 and GLR3.5, GLR3.3-GFP, GLR3.5-GFP, and GFP were transformed into Agrobacterium tumefaciens, and then transiently expressed in N. benthamiana. Confocal microscopy of leaf 
epidermal cells showed that the control GFP signal exhibited a localization in the cells' membranes, cytosols, and nuclei (Figure 2). The fluorescent signals of GLR3.3-GFP and GLR3.5-GFP were colocalized with FLS2-mCherry at the plasma membranes of the cells. It was not observed that GLR3.3 and GLR3.5 colocalized with histone 2B-mCherry at the nuclei. The results suggest that tomato GLR3.3-GFP and GLR3.5-GFP localize at the plasma membrane of a cell.
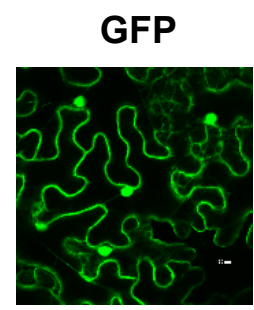

EV-GFP

GLR3.3-GFP
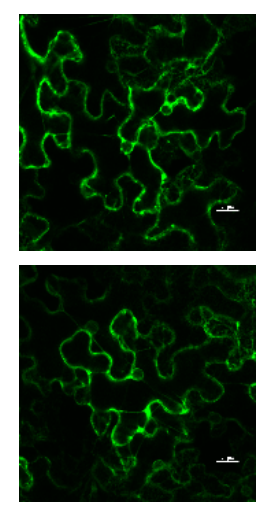
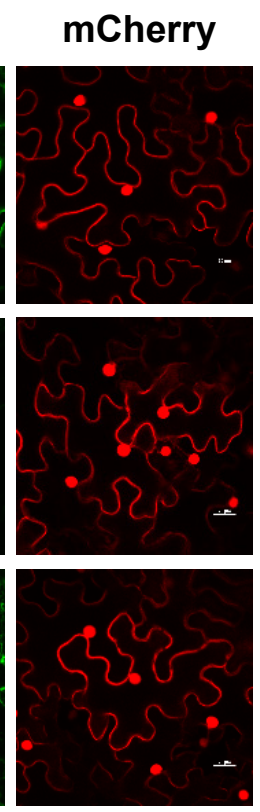
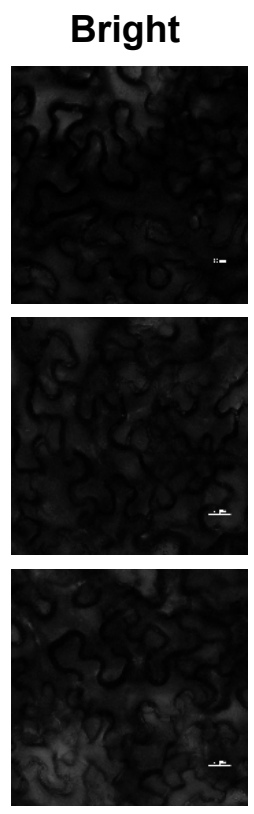

Merge
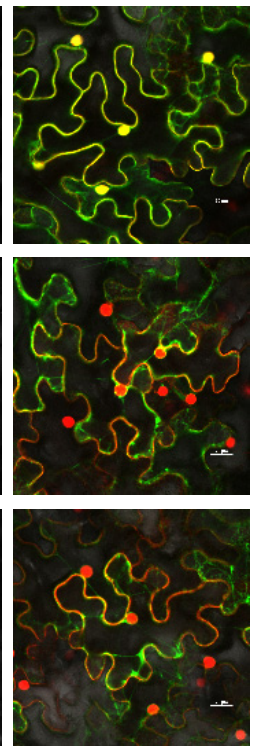

Figure 2. Subcellular localization of GLR3.3 and GLR3.5. Tomato GLRs-GFP were transiently coexpressed with FLS2-mCherry (a plasma membrane localization maker) in $N$. benthamiama leaves. The GFP and mCherry signals were visualized using confocal microscopy $48 \mathrm{~h}$ following the infiltration. Bar $=25 \mu \mathrm{m}$.

\subsection{GLR3.3 and GLR3.5 Function in Plant Defense against B. cinerea}

To investigate the role of GLRs in plant immunity, CRISPR/Cas 9-mediated geneedited tomato GLR3.3 or GLR3.5 knockout plants and glr3.3/3.5 double-mutants were infected with B. cinerea. The results showed that knockout of GLR3.3 and GLR3.5 resulted in an obvious decrease in ФPSII, compared with WT control (Figure 3a,b). Accordingly, the accumulation of $B$. cinerea actin mRNA in leaves significantly increased (Figure 3c) in the $g l r 3.3$ or $g l r 3.5$ mutants. Meanwhile, the $g l r 3.3 / g l r 3.5$ double-mutants showed more attenuation in plant defense when compared with the glr 3.3 and glr 3.5 mutants. These observations suggest that GLR3.3 and GLR3.5 function redundantly to establish resistance against $B$. cinerea. Furthermore, GLR3.3 plays the main role, as glr3.3 mutants were more susceptible to B. cinerea inoculation than glr3.5 mutants. On this basis, GLR3.3 was selected for further study.

\subsection{Recognition of Glu and Gly by GLRs Triggered Electrical Signaling in the Immune Response}

As Glu or Gly can be recognized by GLRs to trigger membrane depolarization [33], we determined Glu- or Gly-induced electrical signaling by monitoring the effect of Glu and Gly on membrane potential in tomato leaves. Glu and Gly treatment elicited significant changes in membrane potential in a short time, with an increase in amplitude of about $17-20 \mathrm{mV}$ (Figure 4). Notably, the change in membrane potential induced by Glu and Gly was significantly weakened in $g l r 3.3$ mutants. These findings suggest that electrical signaling in tomato leaves, induced by Glu or Gly, is partly dependent on GLR3.3. 
(a)

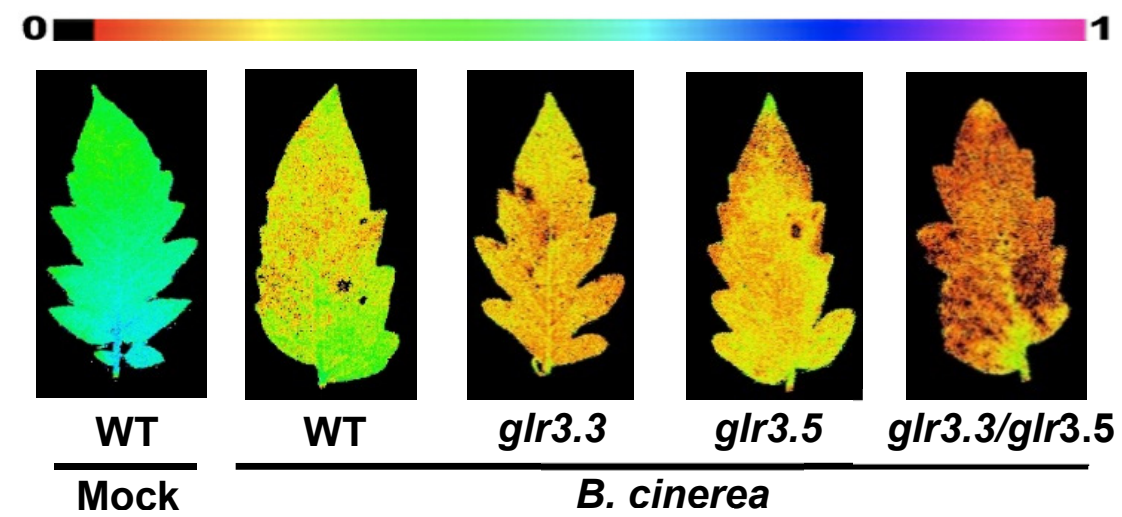

(b)

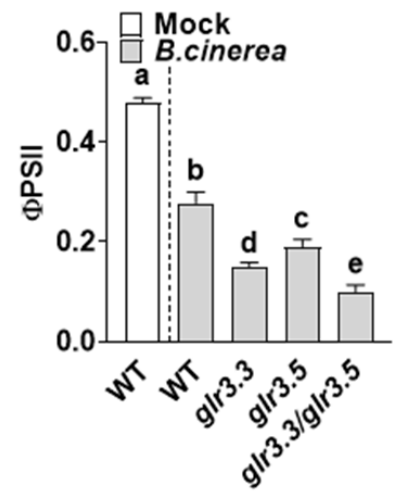

(c)

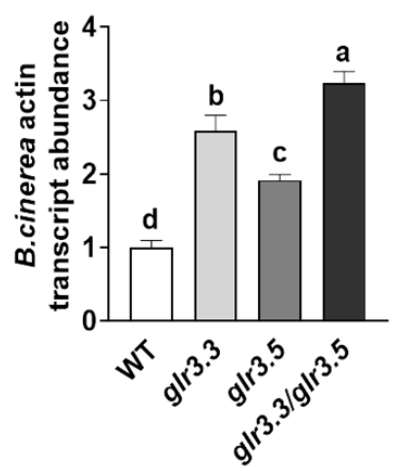

Figure 3. Effects of GLR3.3 and GLR3.5 editing on plant defense against B. cinerea inoculation in tomato: (a) pseudocolor images of tomato leaves showing ФPSII at $3 \mathrm{dpi}$; (b) quantification of ФPSII at $3 \mathrm{dpi}$; (c) transcript abundance of $B$. cinerea actin in tomato leaves inoculated with $B$. cinerea at $1 \mathrm{dpi}$. The results in panels $(\mathbf{b}, \mathbf{c})$ are presented as mean values $\pm \mathrm{SD} ; n=4$. Statistically significant differences between treatments ( $p<0.05$, Tukey's test) are shown by different letters. The experiments described above were carried out three times, with the same findings each time.

(a)

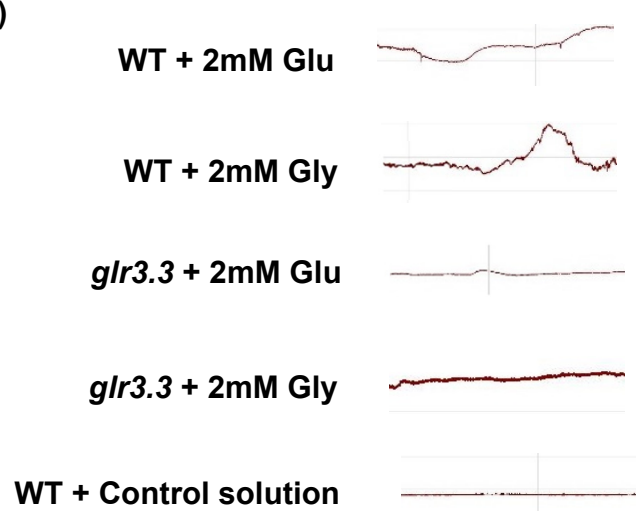

(b)

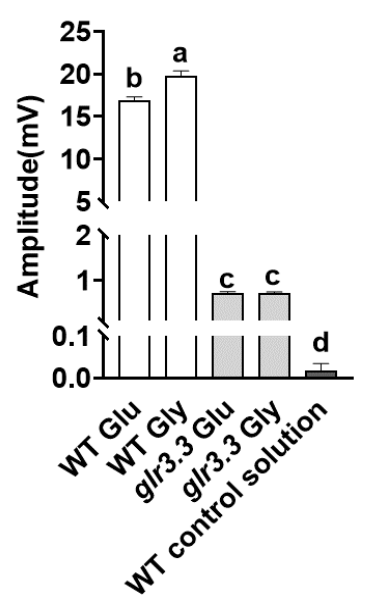

Figure 4. Glu or Gly affects the membrane potential of WT and glr3.3 leaves: (a) typical membrane potential changes in tomato WT or glr3.3 mutant leaves treated with Glu or Gly; (b) quantification of membrane potential changes of amplitude. The results in panel $(\mathbf{b})$ are presented as mean values $\pm \mathrm{SD} ; n=4$. Statistically significant differences between treatments $(p<0.05$, Tukey's test) are shown by different letters. The experiments described above were carried out three times, with the same findings each time.

The glr3.3 mutants exhibited more sensitivity to $B$. cinerea, which was consistent with the reduction in the Glu- or Gly-induced electrical signals. On the basis of these observations, we hypothesized that the recognition of Glu and Gly by GLRs is critical 
in immunity against $B$. cinerea. To verify this hypothesis, a pharmacological assay was carried out by Glu- or Gly-exogenous treatment. Before B. cinerea inoculation, the WT plants and the glr3.3 mutant were pretreated with Glu, Gly, or $\mathrm{H}_{2} \mathrm{O}$ (control). In the WT plants, the B. cinerea inoculation-induced reduction in $\Phi P S I I$ and the increase in B. cinerea actin mRNA accumulation were significantly alleviated by pretreatment with exogenous Glu or Gly at 3 dpi (Figure 5). However, disease symptoms in the glr3.3 mutant were more severe, and the beneficial effects of Glu and Gly on the resistance against B. cinerea significantly decreased due to the knockout of GLR3.3. Thus, these results indicate that Glu- and Gly-induced plant immunity against B. cinerea partly depends on GLR3.3.

(a)

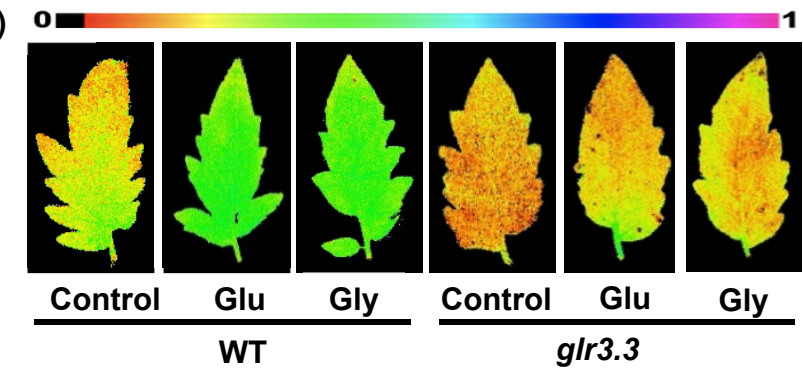

(b)

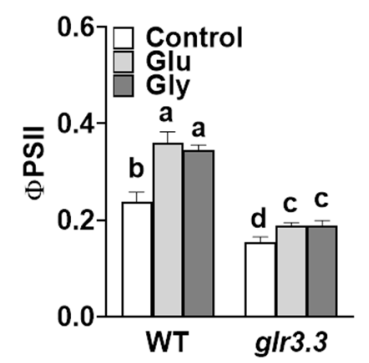

(c)

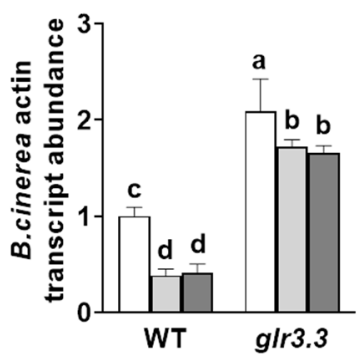

Figure 5. Glu- or Gly-induced immunity against B. cinerea partly depends on GLR3.3. Four-weekold tomato plants were treated with $20 \mathrm{mM}$ Glu, $20 \mathrm{mM}$ Gly, or water once per day for two days before B. cinerea inoculation: (a) pseudocolor images of tomato leaves showing ФPSII at 3 dpi; (b) quantification of $\Phi$ PSII at $3 \mathrm{dpi}$; (c) transcript abundance of B. cinerea actin in tomato leaves inoculated with $B$. cinerea at $1 \mathrm{dpi}$. The results in panels $(\mathbf{b}, \mathbf{c})$ are presented as mean values $\pm S D$; $n=4$. Statistically significant differences between treatments $(p<0.05$, Tukey's test) are shown by different letters. The experiments described above were carried out three times, with the same findings each time.

\section{Discussion}

GLRs are cation-channel proteins that exist in bacteria, plants, and animals. In animals, GLRs are proven to be involved in neurotransmission and immune regulation, and their ligand Glu acts as a signal agent between the two systems [34-36]. In plants, GLRs play a positive role in immunity against biotic stress $[10,12,13]$. Notably, GLR-induced defense against RKNs and insect bites was shown to be associated with electrical signals [3]. However, the relationship between GLR-mediated fungal-disease resistance and electrical signals has not been fully substantiated. Here, we provide convincing evidence demonstrating that tomato GLR3.3- and GLR3.5-modulated plant immunity against the typical fungal pathogen $B$. cinerea is related to electrical signals.

In this study, the role of GLRs in tomato seedling immunity against B. cinerea was unveiled for the first time. The application of the GLR inhibitor DNQX enhanced the susceptibility of tomato plants to B. cinerea (Figure 1). Moreover, knocking out GLR3.3 or GLR3.5 significantly attenuated plant immunity, leading to increased disease symptoms in leaves (Figure 3). These findings support the notion that tomato plants require GLRs to mount an adequate defense against the necrotrophic fungal pathogen $B$. cinerea. Although overexpression of radish GluR inhibits the growth of B. cinerea [37], none of the Arabidopsis glr mutants were found to be more sensitive to B. cinerea [12], suggesting that the function 
of GLRs may differ among species. In the present study, the glr3.3/glr3.5 double-mutants showed a more sensitive phenotype compared with the single-mutant $g l r 3.3$ and $g l r 3.5$. These findings suggest that GLR3.3 and GLR3.5 function redundantly. Notably, a comparison of the phenotypes between $g l r 3.3$ and glr3.5 mutants suggests that GLR3.3 plays the main role in defense against $B$. cinerea.

Electrical signals are a rapid response involved in GLR-mediated plant resistance to biotic stress. Here, the electrical signals induced by Glu or Gly were significantly weakened in glr3.3 mutants. Glu or Gly treatment induced the membrane potential for a short time. However, the variation in amplitude is substantially decreased in glr3.3 mutants (Figure 4). Similarly, in Arabidopsis, the generation and propagation of electrical signals induced by leaf damage are weakened in $g l r 3.3$ and glr3.6 mutants [3]. However, the weakening of wound-induced surface potential changes is manifested in the shortening of the duration, but the amplitude remained the same as WT in Arabidopsis glr3.3 mutants after wounding the leaves. These differences in results may be due to differences in species and treatments. Consistent with our results, the knockout of GLR3.3 inhibits Glu treatmentinduced membrane depolarization in Arabidopsis roots [38]. All of these results suggest that the electrical signals induced by Glu or Gly partly depend on GLR3.3.

Exogenous treatment with Glu induces immune responses to multiple diseases, such as the rice blast fungus Magnaporthe oryza, the necrotrophic fungus Alternaria alternata in tomato fruits, and the soil-borne bacterial pathogen Ralstonia solanacearum [39-41]. Sun et al. (2019) reported that Glu treatment enhances the resistance of tomato fruits against B. cinerea [42]. In the present study, exogenous treatment with Glu or Gly induced immunity against $B$. cinerea in WT plants; however, the benefits of this treatment were significantly inhibited in the glr3.3 mutant (Figure 5). The data presented here demonstrated that GLR3.3 was required for Glu- or Gly-induced immunity against $B$. cinerea. Thus, these findings suggest that the $B$. cinerea resistance induced by Glu or Gly is partly dependent on GLR3.3.

Based on the data provided here, we propose that GLRs are involved in defense responses to $B$. cinerea through electrical signals. Considering the phytohormone-mediated immunity, the salicylic acid signaling pathway facilitates the defense against biotrophic and hemibiotrophic pathogens, while the JA/ethylene signaling pathway functions against necrotrophic pathogens $[43,44]$. An antagonistic relationship between these two pathways is evident in many plant pathosystems [45,46]. However, GLR3.3 has been shown to positively mediate the resistance against the biotrophic pathogen Pst DC3000, while at the same time being essential to immunity against the necrotrophic pathogen $B$. cinerea. Our proposal is reasonable, as GLR3.3 can recognize Glu, which is considered to be a kind of DAMP $[6,47]$. DAMPs trigger early secondary signals and induce expression of JA/ethylene, an SA signaling defense gene. Furthermore, the injection of artificial current into the surface of the stem induces a significant increase in the accumulation of JAs in plants [13]. In accordance with these results, GLR3.3 may play a role in the early phase of plant resistance through Glu- or Gly-induced electrical signals, which respond in seconds or minutes, upstream of the hormone-signaling pathway. The JA signaling pathway may also be activated by electrical signals. In addition, it is well documented that AtGLR3.3 participates in plant resistance by mediating $\left[\mathrm{Ca}^{2+}\right]_{\mathrm{cyt}}$ variation and oxidation responses [12]. The relationship between these pathways and electrical signals in the regulation of plant resistance against $B$. cinerea warrants further investigation.

\section{Conclusions}

The data presented here show that GLR3.3 and GLR3.5 play a positive role in tomato plant defense against the necrotrophic pathogen $B$. cinerea through electrical signals. Our study provides new insights into the plant defense mechanism against $B$. cinerea. Nonetheless, it will be interesting to further investigate the relationship between several signaling pathways induced by GLR, which contribute to plant immunity against fungal pathogens.

Supplementary Materials: The following are available online at https://www.mdpi.com/article/10 .3390/app112311217/s1, Table S1: Primers used in this study, Figure S1: Diagram of the electrode setup. 
Author Contributions: Conceptualization, S.F., C.P. and K.S.; methodology, K.S.; software, S.F. and P.W.; validation, S.F., C.P. and K.S.; formal analysis, S.F., C.H. and Q.M.; investigation, S.F., C.P. and S.D.; resources, K.S.; data curation, S.F. and C.P.; writing-original draft preparation, S.F. and K.S.; writing-review and editing, K.S.; supervision, K.S.; project administration, K.S.; funding acquisition, K.S. All authors have read and agreed to the published version of the manuscript.

Funding: This work was supported by the National Natural Science Foundation of China (31772355, 32172650), the Natural Science Foundation of Zhejiang Province for Distinguished Young Scholars (LR19C150001), the Key Research and Development Program of Zhejiang Province (2021C02040), and the Starry Night Science Fund of the Zhejiang University Shanghai Institute for Advanced Study (SN-ZJU-SIAS-0011).

Institutional Review Board Statement: Not applicable.

Informed Consent Statement: Not applicable.

Data Availability Statement: The raw data supporting the conclusions of this article will be made available by the authors, without undue reservation.

Acknowledgments: The authors would like to extend their sincere appreciation to the National Natural Science Foundation of China, the Natural Science Foundation of Zhejiang Province, the Key Research and Development Program of Zhejiang Province and the Starry Night Science Fund of the Zhejiang University Shanghai Institute for Advanced Study for their financial support.

Conflicts of Interest: The authors declare no conflict of interest.

\section{References}

1. Gilroy, S.; Suzuki, N.; Miller, G.; Choi, W.G.; Toyota, M.; Devireddy, A.R.; Mittler, R. A tidal wave of signals: Calcium and ROS at the forefront of rapid systemic signaling. Trends Plant Sci. 2014, 19, 623-630. [CrossRef]

2. Hedrich, R.; Salvador-Recatala, V.; Dreyer, I. Electrical wiring and long-distance plant communication. Trends Plant Sci. 2016, 21, 376-387. [CrossRef]

3. Mousavi, S.A.; Chauvin, A.; Pascaud, F.; Kellenberger, S.; Farmer, E.E. Glutamate receptor-like genes mediate leaf-to-leaf wound signaling. Nature 2013, 500, 422-426. [CrossRef]

4. Choi, W.G.; Miller, G.; Wallace, I.; Harper, J.; Mittler, R.; Gilroy, S. Orchestrating rapid long-distance signaling in plants with Ca ${ }^{2+}$, ROS and electrical signals. Plant J. 2017, 90, 698-707. [CrossRef]

5. Marcec, M.J.; Gilroy, S.; Poovaiah, B.W.; Tanaka, K. Mutual interplay of $\mathrm{Ca}^{2+}$ and ROS signaling in plant immune response. Plant Sci. 2019, 283, 343-354. [CrossRef]

6. Toyota, M.; Spencer, D.; Sawai-Toyota, S.; Jiaqi, W.; Zhang, T.; Koo, A.J.; Howe, G.A.; Gilroy, S. Glutamate triggers long-distance, calcium-based plant defense signaling. Science 2018, 361, 1112-1115. [CrossRef]

7. Wudick, M.M.; Michard, E.; Oliveira, N.C.; Feijo, J.A. Comparing plant and animal glutamate receptors: Common traits but different fates? J. Exp. Bot. 2018, 69, 4151-4163. [CrossRef]

8. Ni, J.; Yu, Z.; Du, G.; Zhang, Y.; Taylor, J.L.; Shen, C.; Xu, J.; Liu, X.; Wang, Y.; Wu, Y. Heterologous expression and functional analysis of rice GLUTAMATE RECEPTOR-LIKE family indicates its role in glutamate triggered calcium flux in rice roots. Rice 2016, 9, 9. [CrossRef] [PubMed]

9. Aouini, A.; Matsukura, C.; Ezura, H.; Asamizu, E. Characterisation of 13 glutamate receptor-like genes encoded in the tomato genome by structure, phylogeny and expression profiles. Gene 2012, 493, 36-43. [CrossRef] [PubMed]

10. Li, F.; Wang, J.; Ma, C.; Zhao, Y.; Wang, Y.; Hasi, A.; Qi, Z. Glutamate receptor-like channel3.3 is involved in mediating glutathionetriggered cytosolic calcium transients, transcriptional changes, and innate immunity responses in Arabidopsis. Plant Physiol. 2013, 162, 1497-1509. [CrossRef] [PubMed]

11. Nguyen, C.T.; Kurenda, A.; Stolz, S.; Chetelat, A.; Farmer, E.E. Identification of cell populations necessary for leaf-to-leaf electrical signaling in a wounded plant. Proc. Natl. Acad. Sci. USA 2018, 115, 10178-10183. [CrossRef]

12. Manzoor, H.; Kelloniemi, J.; Chiltz, A.; Wendehenne, D.; Pugin, A.; Poinssot, B.; Garcia-Brugger, A. Involvement of the glutamate receptor AtGLR3.3 in plant defense signaling and resistance to Hyaloperonospora arabidopsidis. Plant J. 2013, 76, 466-480. [CrossRef] [PubMed]

13. Wang, G.; Hu, C.; Zhou, J.; Liu, Y.; Cai, J.; Pan, C.; Wang, Y.; Wu, X.; Shi, K.; Xia, X.; et al. Systemic root-shoot signaling drives jasmonate-based root defense against nematodes. Curr. Biol. 2019, 29, 3430-3438. [CrossRef] [PubMed]

14. Darwin, C.R. Insectivorous Plants; John Murray: London, UK, 1875.

15. Burdon-Sanderson, J.S. Note on the electrical phenomena which accompany irritation of the leaf of Dionæa muscipula. Proc. R. Soc. Lond. 1873, 21, 495-496.

16. Sukhova, E.; Akinchits, E.; Sukhov, V. Mathematical models of electrical activity in plants. J. Membr. Biol. 2017, 250, 407-423. [CrossRef] 
17. Li, J.H.; Fan, L.F.; Zhao, D.J.; Zhou, Q.; Yao, J.P.; Wang, Z.Y.; Huang, L. Plant electrical signals: A multidisciplinary challenge. J. Plant Physiol. 2021, 261, 153418. [CrossRef] [PubMed]

18. Garcia-Servin, M.A.; Mendoza-Sanchez, M.; Contreras-Medina, L.M. Electrical signals as an option of communication with plants: A review. Theor. Exp. Plant Physiol. 2021, 33, 125-139. [CrossRef]

19. Li, M.; Wang, F.; Li, S.; Yu, G.; Wang, L.; Li, Q.; Zhu, X.; Li, Z.; Yuan, L.; Liu, P. Importers drive leaf-to-leaf jasmonic acid transmission in wound-induced systemic immunity. Mol. Plant 2020, 13, 1485-1498. [CrossRef]

20. Farmer, E.E.; Gasperini, D.; Acosta, I.F. The squeeze cell hypothesis for the activation of jasmonate synthesis in response to wounding. New Phytol. 2014, 204, 282-288. [CrossRef]

21. Ding, S.; Shao, X.; Li, J.; Ahammed, G.J.; Yao, Y.; Ding, J.; Hu, Z.; Yu, J.; Shi, K. Nitrogen forms and metabolism affect plant defence to foliar and root pathogens in tomato. Plant Cell Environ. 2021, 44, 1596-1610. [CrossRef]

22. Li, X.; Yang, R.; Chen, H. The Arabidopsis thaliana Mediator subunit MED8 regulates plant immunity to Botrytis Cinerea through interacting with the basic helix-loop-helix (bHLH) transcription factor FAMA. PLoS ONE 2018, 13, e193458. [CrossRef]

23. Dean, R.; Van Kan, J.A.; Pretorius, Z.A.; Hammond-Kosack, K.E.; Di Pietro, A.; Spanu, P.D.; Rudd, J.J.; Dickman, M.; Kahmann, R.; Ellis, J.; et al. The Top 10 fungal pathogens in molecular plant pathology. Mol. Plant Pathol. 2012, 13, 414-430. [CrossRef]

24. Bai, Y.; Lindhout, P. Domestication and breeding of tomatoes: What have we gained and what can we gain in the future? Ann. Bot. 2007, 100, 1085-1094. [CrossRef] [PubMed]

25. Wang, X.; Zhou, X.; Cai, Z.; Guo, L.; Chen, X.; Chen, X.; Liu, J.; Feng, M.; Qiu, Y.; Zhang, Y.; et al. A Biocontrol Strain of Pseudomonas aeruginosa CQ-40 Promote Growth and Control Botrytis cinerea in Tomato. Pathogens 2020, 10, 22. [CrossRef]

26. Li, H.; Jiang, X.; Lv, X.; Ahammed, G.J.; Guo, Z.; Qi, Z.; Yu, J.; Zhou, Y. Tomato GLR3.3 and GLR3.5 mediate cold acclimation-induced chilling tolerance by regulating apoplastic $\mathrm{H}_{2} \mathrm{O}_{2}$ production and redox homeostasis. Plant Cell Environ. 2019, 42, 3326-3339. [CrossRef]

27. Hu, C.; Duan, S.; Zhou, J.; Yu, J. Characteristics of herbivory/wound-elicited electrical signal transduction in tomato. Front. Agric. Sci. Eng. 2021, 8, 292-301.

28. Zhang, H.; Hu, Z.; Lei, C.; Zheng, C.; Wang, J.; Shao, S.; Li, X.; Xia, X.; Cai, X.; Zhou, J.; et al. A Plant phytosulfokine peptide initiates auxin-dependent immunity through cytosolic $\mathrm{Ca}^{2+}$ signaling in tomato. Plant Cell 2018, 30, 652-667. [CrossRef] [PubMed]

29. Zhang, S.; Li, X.; Sun, Z.; Shao, S.; Hu, L.; Ye, M.; Zhou, Y.; Xia, X.; Yu, J.; Shi, K. Antagonism between phytohormone signaling underlies the variation in disease susceptibility of tomato plants under elevated $\mathrm{CO}_{2}$. J. Exp. Bot. 2015, 66, 1951-1963. [CrossRef]

30. Genty, B.; Briantais, J.M.; Baker, N.R. The relationship between the quantum yield of photosynthetic electron-transport and quenching of chlorophyll fluorescence. Biochim. Biophys. Acta 1989, 990, 87-92. [CrossRef]

31. Ma, Q.; Liu, Y.; Fang, H.; Wang, P.; Ahammed, G.J.; Zai, W.; Shi, K. An essential role of mitochondrial alpha-ketoglutarate dehydrogenase E2 in the basal immune response against bacterial pathogens in tomato. Front. Plant Sci. 2020, $11,579772$. [CrossRef]

32. Liao, Y.; Tian, M.; Zhang, H.; Li, X.; Wang, Y.; Xia, X.; Zhou, J.; Zhou, Y.; Yu, J.; Shi, K.; et al. Salicylic acid binding of mitochondrial alpha-ketoglutarate dehydrogenase E2 affects mitochondrial oxidative phosphorylation and electron transport chain components and plays a role in basal defense against tobacco mosaic virus in tomato. New Phytol. 2015, 205, 1296-1307. [CrossRef]

33. Stephens, N.R.; Qi, Z.; Spalding, E.P. Glutamate receptor subtypes evidenced by differences in desensitization and dependence on the GLR3.3 and GLR3.4 genes. Plant Physiol. 2008, 146, 529-538. [CrossRef] [PubMed]

34. Boldyrev, A.A.; Carpenter, D.O.; Johnson, P. Emerging evidence for a similar role of glutamate receptors in the nervous and immune systems. J. Neurochem. 2005, 95, 913-918. [CrossRef]

35. Fazio, F.; Ulivieri, M.; Volpi, C.; Gargaro, M.; Fallarino, F. Targeting metabotropic glutamate receptors for the treatment of neuroinflammation. Curr. Opin. Pharmacol. 2018, 38, 16-23. [CrossRef]

36. Ganor, Y.; Levite, M. The neurotransmitter glutamate and human T cells: Glutamate receptors and glutamate-induced direct and potent effects on normal human T cells, cancerous human leukemia and lymphoma T cells, and autoimmune human T cells. J. Neural Transm. 2014, 121, 983-1006. [CrossRef] [PubMed]

37. Kang, S.; Kim, H.B.; Lee, H.; Choi, J.Y.; Heu, S.; Oh, C.J.; Kwon, S.I.; An, C.S. Overexpression in Arabidopsis of a plasma membrane-targeting glutamate receptor from small radish increases glutamate-mediated $\mathrm{Ca}^{2+}$ influx and delays fungal infection. Mol. Cells 2006, 21, 418-427.

38. Qi, Z.; Stephens, N.R.; Spalding, E.P. Calcium entry mediated by GLR3.3, an Arabidopsis glutamate receptor with a broad agonist profile. Plant Physiol. 2006, 142, 963-971. [CrossRef]

39. Kadotani, N.; Akagi, A.; Takatsuji, H.; Miwa, T.; Igarashi, D. Exogenous proteinogenic amino acids induce systemic resistance in rice. BMC Plant Biol. 2016, 16, 60. [CrossRef] [PubMed]

40. Seo, S.; Nakaho, K.; Hong, S.W.; Takahashi, H.; Shigemori, H.; Mitsuhara, I. L-Histidine induces resistance in plants to the bacterial pathogen ralstonia solanacearum partially through the activation of ethylene signaling. Plant Cell Physiol. 2016, 57, 1932-1942. [CrossRef]

41. Yang, J.; Sun, C.; Fu, D.; Yu, T. Test for L-glutamate inhibition of growth of Alternaria alternata by inducing resistance in tomato fruit. Food Chem. 2017, 230, 145-153. [CrossRef]

42. Sun, C.; Jin, L.; Cai, Y.; Huang, Y.; Zheng, X.; Yu, T. L-Glutamate treatment enhances disease resistance of tomato fruit by inducing the expression of glutamate receptors and the accumulation of amino acids. Food Chem. 2019, 293, 263-270. [CrossRef] 
43. Li, N.; Han, X.; Feng, D.; Yuan, D.; Huang, L.J. Signaling crosstalk between salicylic acid and ethylene/jasmonate in plant defense: Do we understand what they are whispering? Int. J. Mol. Sci. 2019, 20, 671. [CrossRef] [PubMed]

44. Farmer, E.E.; Gao, Y.Q.; Lenzoni, G.; Wolfender, J.L.; Wu, Q. Wound- and mechanostimulated electrical signals control hormone responses. New Phytol. 2020, 227, 1037-1050. [CrossRef] [PubMed]

45. Zhang, Y.; Song, R.F.; Yuan, H.M.; Li, T.T.; Wang, L.F.; Lu, K.K.; Guo, J.X.; Liu, W.C. Overexpressing the N-terminus of CATALASE2 enhances plant jasmonic acid biosynthesis and resistance to necrotrophic pathogen Botrytis cinerea B05.10. Mol. Plant Pathol. 2021, 22, 1226-1238. [CrossRef] [PubMed]

46. Caarls, L.; Van der Does, D.; Hickman, R.; Jansen, W.; Verk, M.C.; Proietti, S.; Lorenzo, O.; Solano, R.; Pieterse, C.M.; Van Wees, S.C. Assessing the role of ethylene response factor transcriptional repressors in salicylic acid-mediated suppression of jasmonic acid-responsive genes. Plant Cell Physiol. 2017, 58, 266-278. [CrossRef]

47. Tanaka, K.; Heil, M. Damage-associated molecular patterns (DAMPs) in plant innate immunity: Applying the danger model and evolutionary perspectives. Annu. Rev. Phytopathol. 2021, 59, 53-75. [CrossRef] 